\title{
“Dupatta” Entanglement: Cause of Head Injury in Female Pillion Riders on Motorcycles
}

\author{
Sushilkumar M. Shinde ${ }^{1} \quad$ Rajesh Kumar Sharma ${ }^{1}$ \\ ${ }^{1}$ Department of Neurosurgery, Postgraduate Institute of Medical \\ Education and Research \& Dr. Ram Manohar Lohia Hospital, \\ New Delhi, India \\ Indian J Neurosurg 2018;7:43-45
}

\author{
S. Bhaskar ${ }^{1}$ Ajay Chaudhary ${ }^{1}$
}

\begin{abstract}
Address for correspondence Dr. Sushilkumar M. Shinde, MS, Department of Neurosurgery, Dr. Ram Manohar Lohia Hospital, New Delhi, Delhi 110001, India (e-mail: drsushil28@gmail.com).
\end{abstract}

\begin{abstract}
Road traffic accidents are a major cause of head injury. Direct head-on collision, hit by vehicle, and overturning of vehicle are some of the modes of road traffic accidents leading to head injury. A dupatta is an accessory worn by many females in the Indian subcontinent. It is wrapped around the neck like a scarf. It can get entangled in the vehicle leading to skidding of vehicle and consequent traumatic injury. There are many reported cases of cervical spine injury by this mechanism. However, this can also result

Keywords in head injury due to direct impact. In this article we report two cases of head injury

- dupatta

- entanglement

- head injury caused by entanglement of dupatta in the tire of a two-wheeler vehicle. In both cases the dupatta got entangled in the tire of vehicle leading to skidding of bike and then leading to head injury.
\end{abstract}

\section{Introduction}

Road traffic accidents are a major cause of head injury. Direct head-on collision, hit by vehicle, and overturning of vehicle are some of the modes of road traffic accidents leading to head injury.

A dupatta is an accessory worn by many females in the Indian subcontinent. It is wrapped around the neck like a scarf. ( - Fig. 1a) It can get entangled in the vehicle leading to skidding of vehicle and consequent traumatic injury. There are reported cases of cervical spine injury by this mechanism.

In this article, we report two cases of head injury to female pillion riders caused by entanglement of dupatta in the tire of a two-wheeler vehicle.

\section{Case Report}

Case 1

A 27-year-old female patient was brought to the emergency as a case of head injury due to skidding of two-wheeler vehicle. The patient was an unhelmeted pillion rider. She was wearing a dupatta that accidentally got entangled in the rear tire of the vehicle. This led to the motorcycle skidding and both riders falling off it. She was unconscious for 30 minutes with no history of seizures or vomiting. The driver was unhurt.

On examination the Glasgow coma scale (GCS) was E3V4M6. Ligature mark was present around the neck. There were no associated chest, abdominal, long bone, or cervical spine injuries. Noncontrast computed tomography (NCCT) of the head showed left frontal and temporal contusion with left temporal acute subdural hematoma (SDH) with mass effect with midline shift to right ( - Fig. 2a).

The patient underwent left frontotemporoparietal decompressive craniectomy and evacuation of frontal and temporal contusions with lax duraplasty ( - Fig. $2 \mathbf{b}$ ). The bone was placed in the abdominal parietal wall. Postoperative course was uneventful with the patient discharged on 10th day with GCS of E4V5M6. The patient underwent cranioplasty after 4 months.

\section{Case 2}

A 20-year-old woman, an unhelmeted pillion rider on a motorcycle, was brought to the emergency after falling from the bike. She was holding her 9-month-old child in her lap received

December 28, 2015 accepted after revision

February 10, 2016

published online

April 12, 2017
DoI http://dx.doi.org/

10.1055/s-0036-1584590. ISSN 2277-954X.
Copyright @2018 Neurological

Surgeons' Society of India
License terms

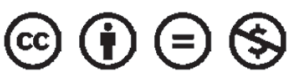



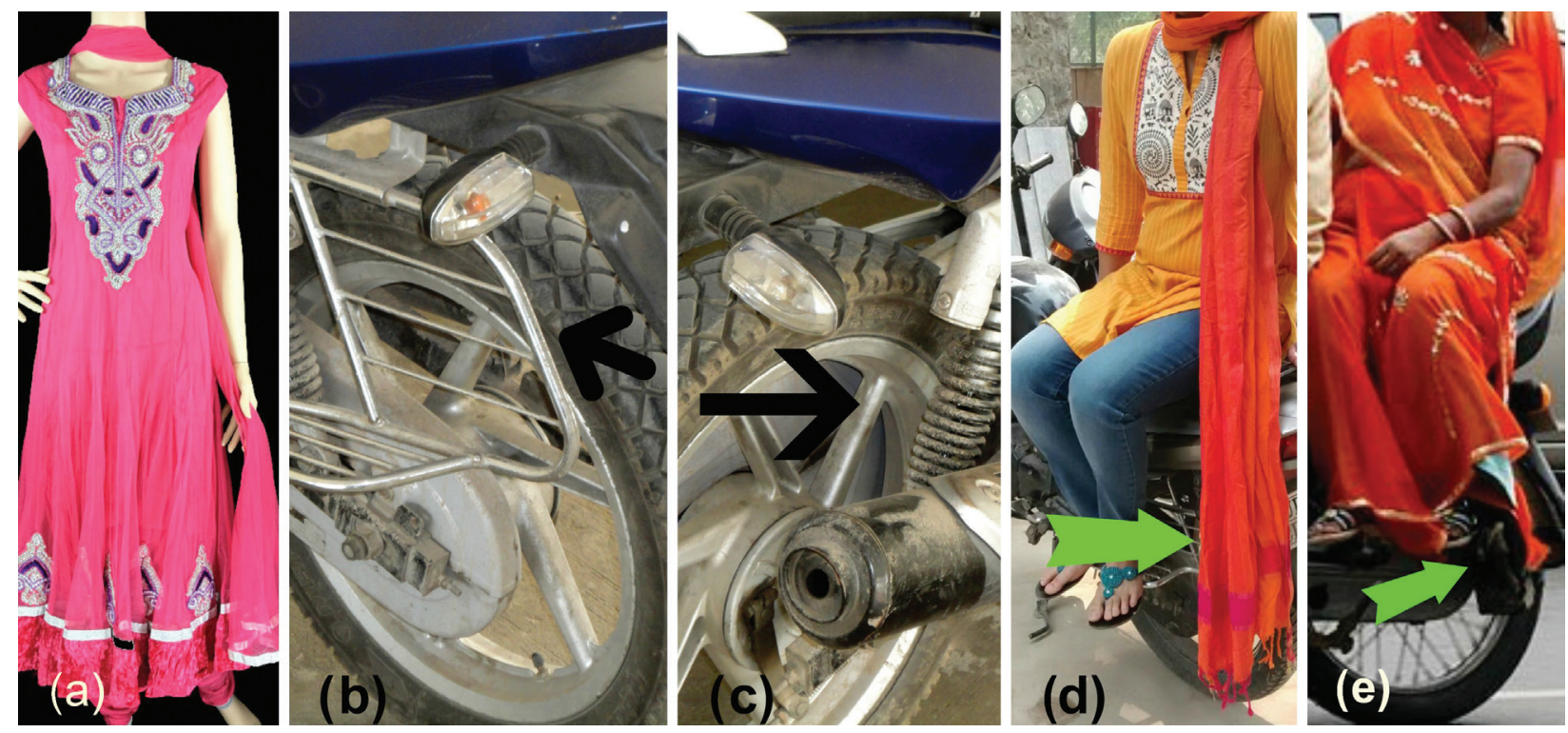

Fig. 1 (a) Traditional Indian dupatta; (b and c) improperly designed sari guard, arrows pointing toward space between tire and sari guard; (d) image showing dupatta that could get entangled in the tire; (e) image showing sari that could get entangled in the tire.

while riding the bike. She was wearing a dupatta that accidentally got caught in the rear tire of the vehicle, causing the accident. In this case also, the driver was unhurt.

She was unconscious for 5 minutes with no other sequelae. On examination GCS was 15/15, and ligature mark was present on her neck. NCCT of the head was normal. There was no cervical spine injury. The patient was managed with analgesics. Her child also sustained mild head injury that was managed medically.

\section{Discussion}

Fall, road traffic accident, and assault are some of the common modes of head injury. Direct head-on collision, being hit by vehicle, and overturning or slipping of a vehicle are some of the modes of road traffic accidents leading to head injury.

A dupatta is an accessory worn by many females in Indian subcontinent. It is wrapped around the neck like a scarf (-Fig. 1a). It is a clothing accessory worn with salwar kameez. In the Indian subcontinent female pillion riders usually sit facing toward their left side. Motorbikes are usually provided with sari guards to prevent clothes from getting entangled in the tire, but the improperly designed

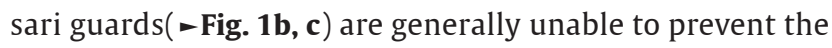
dupatta or pallu from getting entangled. The dupatta or sari's pallu (loose end of the sari) (-Fig. 1d, e) worn by pillion rider can get entangled in the tire of the motorbike.

(a)
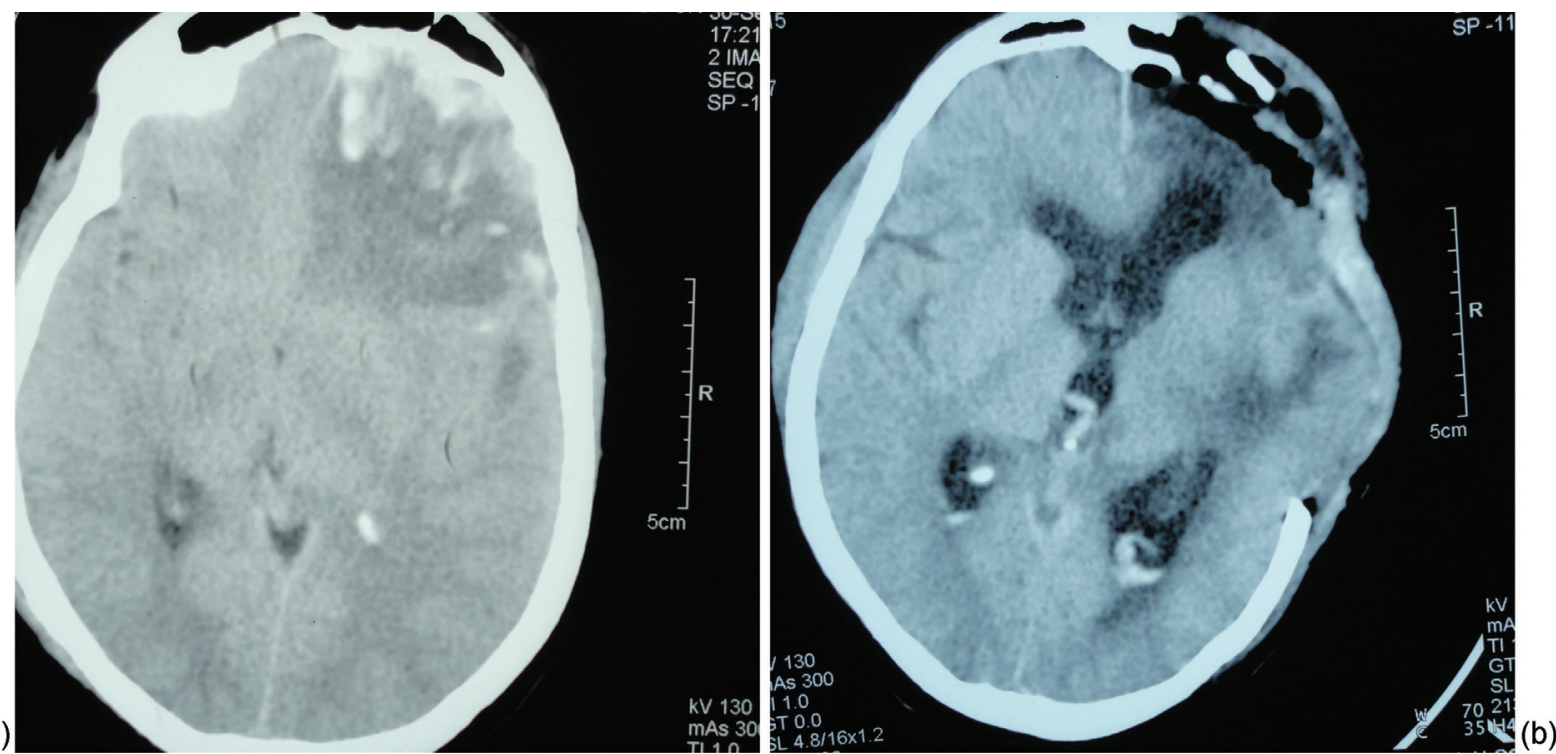

Fig. 2 (a) NCCT of the head showing left frontal contusion; (b) NCCT of the head showing postoperative craniectomy defect. 
Moreover, these sari guards are placed only on one side (left) of the bike. In the aforementioned cases, the dupatta got entangled in the tire of vehicle leading to slipping of the bike with consequent head trauma. Both the patients also had ligature mark around the neck, but luckily no cervical spine injuries occurred.

The first written case report of accidental strangulation in an adult was the world famous dancer Isadora Duncan who died on September 14, 1929.' Cases are documented where cloth entwined in a cycle-powered rickshaw. ${ }^{3}$ There is one reported case of dupatta causing cervical spine injury due to entanglement in a crop thresher. ${ }^{1}$ A case of entanglement of sari in a moving crop thresher leading to strangulation and scalp and ear avulsion is also reported. ${ }^{4}$ There are reported cases of accidental strangulation of the neck caused by dupatta. ${ }^{1}$ Head injury caused by dupatta entanglement around the neck has not been reported.

Traumatic injuries such as these can be prevented by following simple measures such as wearing dupatta properly so that it does not get entangled in the wheel of vehicle. Both the dupatta and the pallu should not hang freely while a woman is sitting on the bike. Also, the design of sari guards needs to be such that it does not allow the entanglement of the dupatta. One needs to install sari guards in such a manner that it protects the pillion rider's feet and clothes on both sides. In both cases, the women were not wearing a helmet. Wearing helmet must be strictly followed in motorcycle riders. Therefore, following simple regulations, injuries such as this are preventable.

\section{References}

1 Jain V, Agrawal M, Dabas V, Kashyap A, Sural S, Dhal A. Dupatta (scarf): a unique cause of cervical spine injury in females. Injury 2008;39(3):334-338

2 Gowens PA, Davenport RJ, Kerr J, Sanderson RJ, Marsden AK. Survival from accidental strangulation from a scarf resulting in laryngeal rupture and carotid artery stenosis: the "Isadora Duncan syndrome." A case report and review of literature. Emerg Med J 2003;20(4):391-393

3 Kohli A, Verma SK, Agarwal BB. Accidental strangulation in a rickshaw. Forensic Sci Int 1996;78(1):7-11

4 Zine KU, Tandle RM, Varma NM, Jambure MP. Accidental ligature strangulation with avulsion of scalp. J Indian Acad Forensic Med 2011 33(3). Available at http://medind.nic.in/jal/t11/ i3/jalt11i3p267.pdfIndian 